Check for updates

Cite this: RSC Adv., 2017, 7, 41063

Received 22nd April 2017

Accepted 1st August 2017

DOI: 10.1039/c7ra04521b

rsc.li/rsc-advances

\section{Detection of tumor marker miRNA21 based on phosphorescent resonance energy transfer of Mn-ZnS QDs $\uparrow$}

\begin{abstract}
Jinzhi Lv, Yanming Miao and Guiqin Yan (D) *
Since miRNA21 is a marker of many human tumors, trace detection of miRNA21 contributes to early tumor diagnosis. However, conventional methods are limited by complex sample preprocessing, high costs, or the interference from background fluorescence in biological fluids. Thus, developing simple and cheap miRNA21 detection methods from biological fluids is very urgent. Our highlights are that: the miRNA-21 detection system based on phosphorescent resonance energy transfer solves the limitations of conventional methods, avoids the interference from the background fluorescence and scattering in biological fluids, eliminates complex sample preprocessing, and is more feasible for miRNA-21 detection in biological fluids. The principle of detection is that: QDs/PDADMAC $\left(\mathrm{QDs}^{+}\right)$nanohybrids were prepared from Mn-ZnS RTP QDs and cationic poly(diallyldimethylammonium chloride). Then a miRNA-21 sequence nanoprobe was built via the interaction between the $\mathrm{QDs}^{+}$and 6-carboxy-X-rhodamine-DNA (ROX-DNA). The PRET between the $\mathrm{QDs}^{+}$and ROX-DNA could quench the phosphorescence of the $\mathrm{QDs}^{+}$. After the gradual addition of the miRNA21 sequence, owing to the double-stranded structures formed between miRNA21 and ROX-DNA, the ROX-DNA desorbed from the surfaces of the QDs ${ }^{+}$, which gradually restored the phosphorescence of the $\mathrm{QDs}^{+}$. This nanoprobe had a detection limit of $1.60 \mathrm{nM}$ and a detection range of $8-80 \mathrm{nM}$. This nanoprobe is more feasible for quantitative detection of miRNA21 in biological samples and has prospects in the medical diagnosis of tumors.
\end{abstract}

\section{Introduction}

Nucleic acid detection (specifically DNA and RNA detection) has been well appreciated in basic research of clinical diagnosis, forensic analysis, biology and biomedicine. ${ }^{\mathbf{1 , 2}}$ In particular, micro-RNAs (miRNAs) are a group of small endogenetic nonencoding nucleotide sequences (about 18-25 bases) and play critical roles in hematopoietic cell differentiation, cell cycle regulation, metabolism, tumor metastasis, stem cell differentiation and virus replication. ${ }^{3}$ Specific miRNAs can be used as tumor markers to monitor the development of some tumors. ${ }^{4}$ The upregulation of miRNA21 concentrations in many types of human tumors and adjacent tissues has been confirmed, while serum miRNA21 overexpression has been proved in different cancers, such as diffused-typed b cell lymphoma, ovarian cancer, prostate cancer or breast cancer. ${ }^{5-8}$ Thus, miRNA21 can be used as a marker of many human tumors, and trace detection of miRNA21 contributes to early tumor diagnosis. The existing miRNA detection methods, including quantitative polymerase chain reaction, ${ }^{9}$ RNA imprinting, ${ }^{10}$

Shanxi Normal University, Linfen 041004, PR China. E-mail: gqyan2013@163.com; Fax: +86-357-2051243

† Electronic supplementary information (ESI) available. See DOI: 10.1039/c7ra04521b electrochemistry, ${ }^{\mathbf{1 1}, 12}$ miRNA arrays ${ }^{\mathbf{1 3}}$ and surface enhanced Raman spectroscopy, ${ }^{\mathbf{1 4}}$ are limited by complex sample treatment and high costs. Thus, developing simple, cheap, accurate and sensitive RNA detection methods is very urgent.

In recent years, quantum dots (QDs), with unique photophysical properties, are considered as ideal fluorescent markers and have been widely applied into biological sensors and biological imaging. However, the accuracy of fluorescent QDsbased probes is largely reduced due to the severe background disturbances of fluorescence and scattering light from real biological or environmental samples, which bring about the problem of complex pretreatment. On the contrary, roomtemperature phosphorescence (RTP) has longer lifetime than fluorescence and thus avoids such disturbances. ${ }^{15-17}$ Thus, RTP QDs can be used to more stably detect the molecules of biological fluids. Moreover, RTP probes are more selective due to the less frequency than fluorescence. ${ }^{18}$ RTP probes also eliminate the complicated pretreatment that is needed by biological sample analysis. ${ }^{16,17,19}$ Given these advantages, RTP QDs probes show their high prospects in biomolecular detection. ${ }^{\mathbf{1 6 2 0 - 2 8}}$ However, there is no study about the detection of miRNAs by using the RTP of QDs.

In this study, water-soluble 3-mercaptopropionic acid (MPA)coated Mn-doped ZnS (Mn-ZnS) QDs were prepared first. Then based on the principle of phosphorescent resonance energy 


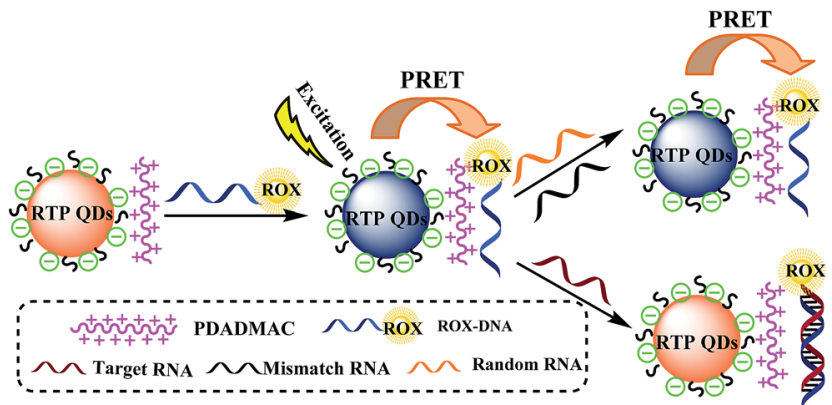

Fig. 1 Schematic representation of the designed nanoprobe for detection of miRNA-21 based on the PRET system.

transfer (PRET), QDs ${ }^{+} /$ROX-DNA detection probes were built and used to detect specific miRNA-21 sequences. Also its detection mechanism was discussed (Fig. 1). The working principle is that with poly(diallyldimethylammonium chloride) (PDADMAC) as a connecting bridge, the $\mathrm{QDs}^{+}$and ROX-DNA were adsorbed together via electrostatic interaction to a miRNA21 detection probe system. The phosphorescence intensity of $\mathrm{QDs}^{+}$was gradually reduced by the PRET between $\mathrm{QDs}^{+}$and ROX, but was gradually restored after the addition of the target sequence miRNA21 when the ROX was desorbed from the surfaces of QDs ${ }^{+}$. Based on this principle, RTP probes were established for quantitative measurement of specific miRNA21 sequence. Since this method was based on the RTP of QDs, it effectively avoided the background fluorescence or scattering light of biological samples, and eliminated complex sample pretreatment, so it is especially feasible for trace detection of miRNA21 in organisms.

\section{Experimental section}

\subsection{Materials and reagents}

The DNA and RNA sequences were prepared in Shanghai Biological Engineering Co., Ltd. (China). The details are showed in Table S1. $\dagger \mathrm{Mn}-\mathrm{ZnS}$ QDs were prepared from MPA (J\&K Chemical Co Ltd., China), $\mathrm{Mn}(\mathrm{Ac})_{2} \cdot 4 \mathrm{H}_{2} \mathrm{O}, \mathrm{Zn}(\mathrm{Ac})_{2} \cdot 2 \mathrm{H}_{2} \mathrm{O}$ and $\mathrm{Na}_{2} \mathrm{~S} \cdot 9 \mathrm{H}_{2} \mathrm{O}$ (all Tianjin Kemiou Chemical Reagent Co., Ltd.). Serum sample was purchased from Chongqing Manuik Technology Co. Ltd. (China). All solutions were prepared in ultrapure water $(18.2 \mathrm{M} \Omega \mathrm{cm})$, which was generated by a WaterPro ultrapure water instrument (Labconco, US).

\subsection{Instruments}

The morphological structures of the QDs were studied on a JEM2100 transmission electron microscope (TEM, JEOL Ltd. Japan). RTP was detected by a Cary Eclipse fluorescent spectrophotometer (Varian Co. Ltd, US). Other instruments included a UV-29100 UV/Vis spectrophotometer (Shimadzu, Japan) and a pH meter (Shanghai Lei-ci Co., Ltd, China).

\subsection{Synthesis of Mn-ZnS QDs}

$\mathrm{Mn}-\mathrm{ZnS}$ QDs were prepared as reported before. ${ }^{29-31}$ First, a $250 \mathrm{~mL}$ three-necked bottles was added with $10 \mathrm{~mL}$ of
$0.1 \mathrm{~mol} \mathrm{~L}^{-1} \mathrm{Zn}(\mathrm{Ac})_{2}, 4 \mathrm{~mL}$ of $0.01 \mathrm{~mol} \mathrm{~L}^{-1} \mathrm{Mn}(\mathrm{Ac})_{2}$ and $100 \mathrm{~mL}$ of $0.04 \mathrm{~mol} \mathrm{~L}^{-1}$ MPA. The mixture was adjusted to $\mathrm{pH} 11$ by adding a $1 \mathrm{~mol} \mathrm{~L}^{-1} \mathrm{NaOH}$ solution, and then magnetically stirred for $30 \mathrm{~min}$ at room temperature and argon ventilation. Then the tube was injected with $10 \mathrm{~mL}$ of $0.1 \mathrm{~mol} \mathrm{~L}^{-1} \mathrm{Na}_{2} \mathrm{~S}$ under air isolation, and ventilated with argon gas for $20 \mathrm{~min}$. After ageing in air for 2 hours, the resulting solution was kept at $50{ }^{\circ} \mathrm{C}$ to form MPA-capped Mn-ZnS QDs. Then a same volume of ethanol was added to precipitate the QDs. The resulting solution was centrifuged, washed with ethanol, and dried in a vacuum oven for $24 \mathrm{~h}$, forming powder Mn-ZnS QDs.

\subsection{Synthesis of $\mathrm{QDs}^{+}$}

Then $5 \mathrm{mg}$ of $\mathrm{Mn}-\mathrm{ZnS}$ QD powder was dissolved in appropriate amount of ultrapure water. The new solution was diluted by $100 \mu \mathrm{L}$ of PDADMAC to $10 \mathrm{~mL}(0.35 \mathrm{wt} \%, \mathrm{pH} 7.4)$, evenly shaken and placed still for $10 \mathrm{~min}$. Afterwards, an equal volume of anhydrous ethanol was added. The new solution was shaken evenly and centrifuged. Then the supernatant was discarded to remove the remaining PDADMAC (repeated three times). Finally, the resulting solution was diluted into $5 \mathrm{~mL}$ of ultrapure water to form a Mn-ZnS QD/PDADMAC $\left(\mathrm{QDs}^{+}\right)$nanocomposite solution (1 $\mathrm{mg} \mathrm{mL}^{-1}$, calculated as per $\mathrm{Mn}-\mathrm{ZnS}$ QDs).

\subsection{Procedures of experiment}

To study the effects of ROX-DNA on the RTP intensity of QDs ${ }^{+}$, we first prepared a 1.0 $\mu \mathrm{M}$ ROX-DNA aqueous solution and then added $50 \mu \mathrm{L}$ of the QDs ${ }^{+}$solution to a phosphate buffer solution (PBS, pH 7.4, 0.20 M). Then a series of ROX-DNA solutions at different concentrations were prepared by adding different volumes of ROX-DNA solution. All resulting solutions were diluted to $5 \mathrm{~mL}$, shaken evenly for $30 \mathrm{~min}$, and the RTP at the excitation wavelength $295 \mathrm{~nm}$ was measured. To detect the target RNA, first we dissolved the target RNA in ultrapure water, forming a $1 \mu \mathrm{M}$ RNA solution. Then to $10 \mathrm{~mL}$ colorimetric tubes, $500 \mu \mathrm{L}$ of PBS, $500 \mu \mathrm{L}$ of $1 \mathrm{M} \mathrm{NaCl}, 50 \mu \mathrm{L}$ of $1 \mathrm{mg} \mathrm{mL}^{-1} \mathrm{Mn}-\mathrm{ZnS}$ $\mathrm{QDs}^{+}$and $200 \mu \mathrm{L}$ of $1 \mu \mathrm{M}$ ROX-DNA were added. The tubes were shaken evenly and placed still for $5 \mathrm{~min}$, forming a series of $\mathrm{QDs}^{+} / \mathrm{ROX}$-DNA probes. Then different concentrations of the target miRNA21 sequence ( $8-80 \mathrm{nM}$ ) were added. The resulting mixtures were diluted to $5 \mathrm{~mL}$ by adding ultrapure water, shaken evenly and placed still at $37^{\circ} \mathrm{C}$ for $30 \mathrm{~min}$. Then RTP at $295 \mathrm{~nm}$ was determined. Each experiment was repeated three times.

\subsection{Sample pretreatment}

Serum samples were diluted by 100 times, without any other pretreatment.

\subsection{Sample detection}

To each of $10 \mathrm{~mL}$ colorimetric tubes, $500 \mu \mathrm{L}$ of PBS (pH 7.4, $0.2 \mathrm{M}), 500 \mu \mathrm{L}$ of $1 \mathrm{M} \mathrm{NaCl}, 50 \mu \mathrm{L}$ of $1 \mathrm{mg} \mathrm{mL}{ }^{-1} \mathrm{Mn}-\mathrm{ZnS} \mathrm{QDs}^{+}$ and $200 \mu \mathrm{L}$ of $1 \mu \mathrm{M}$ ROX-DNA were added. The tubes were shaken evenly and placed still for $5 \mathrm{~min}$. After addition of different concentrations of miRNA21, the resulting mixtures 
were all diluted to $5 \mathrm{~mL}$ by adding ultrapure water, shaken evenly and placed still at $37^{\circ} \mathrm{C}$ for $30 \mathrm{~min}$. Then RTP at $295 \mathrm{~nm}$ was determined. Each experiment was conducted in triplicate. Owing to the absence of miRNA21 in the serum samples, we validated the performance of these probes in detecting the miRNA21 in body fluids by using spiked recovery trials (spiked amounts were 10 and $50 \mathrm{nM}$ ). The samples were diluted 100 times, without any other pretreatment.

\section{Results and discussion}

\subsection{Characterization of the MPA-capped Mn-doped ZnS QDs and QDs ${ }^{+}$}

The MPA-capped Mn-ZnS QDs prepared here had the largest emission peak at $590 \mathrm{~nm}$ (Fig. S1A $\dagger$ ). This RTP was attributed to the transition of $\mathrm{Mn}^{2+}{ }^{4} \mathrm{~T}_{1}-{ }^{6} \mathrm{~A}_{1} \cdot{ }^{32}$ The excitation light was absorbed by the ZnS matrix to excite its electrons. The holes asformed captured $\mathrm{Mn}^{2+}$, which interacted with the electrons and holes separately to form composites, leading to the excitation of $\mathrm{Mn}^{2+}$ and the energy release in the form of RTP (about $590 \mathrm{~nm}) .{ }^{21}$ The shape and size of the QDs were characterized by TEM, which showed the diameter was about $3.5 \mathrm{~nm}$ (Fig. S1B $\dagger$ ). The diameter of Mn-doped ZnS QDs was calculated by eqn (1). ${ }^{33}$

$D=9.8127 \times 10^{-7} \lambda^{3}-1.7147 \times 10^{-3} \lambda^{2}+1.0064 \lambda-194.84$

where $D$ is the diameter of the QDs and $\lambda$ is the wavelength of emission maximum. The diameter of prepared Mn-doped Zn S QDs was calculated as $3.5 \mathrm{~nm}$.

\subsection{Spectral properties of Mn-ZnS QDs ${ }^{+}$, ROX-DNA, and QDs}

The phosphorescent emission spectrum (curve a) of $\mathrm{QDs}^{+}$and the ultraviolet absorption spectrum (curve b) of ROX-DNA are showed in Fig. 2. Clearly, $\mathrm{QDs}^{+}$has an emission peak at 590, which is largely overlapped with the maximum absorption peak of ROX-DNA at 587. Thus, efficient PRET occurred between $\mathrm{QDs}^{+}$(the energy donor) and ROX-DNA (the energy receptor),

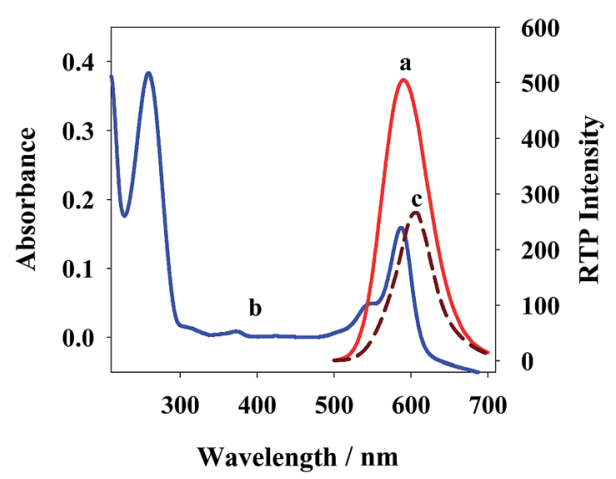

Fig. 2 Normalized spectra of (a) RTP emission of Mn-ZnS QDs ${ }^{+}$ excited at $295 \mathrm{~nm}$, (b) absorption of ROX-DNA, and (c) emission of $\mathrm{Mn}-\mathrm{ZnS} \mathrm{QDs}^{+} / \mathrm{ROX}-\mathrm{DNA}$ excited at $295 \mathrm{~nm}$; all spectra were recorded in PBS buffer (20 mM, pH 7.4). which reduced the phosphorescent intensity of $\mathrm{QDs}^{+}$(curve c). Moreover, after being stored in a refrigerator at $4{ }^{\circ} \mathrm{C}$ for 1 month, the new $\mathrm{QDs}^{+}$only had a $5.3 \%$ reduction of phosphorescent intensity, which proves its high optical stability (Fig. S2†).

At room temperature, the negatively-charged QDs on surfaces in the $\mathrm{pH}$ 7.4 PBS, and the positively-charged PDADMAC aggregated via electrostatic interaction to form positivelycharged QDs ${ }^{+}$. As showed in Fig. 3, the emission spectra of QDs ${ }^{+}$ and QDs are similarly-shaped, except that $\mathrm{QDs}^{+}$has a slightly higher phosphorescence intensity. The possible reason is that PDADMAC can simultaneously bind multiple QDs, which shortens some of the between-dot distances. TEM (Fig. S3†) also proves the occurrence of obvious dot aggregation. The electronhole-caused surface defects in QDs will produce a local electric field. ${ }^{34,35}$ Since the reduced between-dot distances would enhance the local electric field around the QDs and stimulate more-effective excitation from the QDs, ${ }^{36,37}$ more energy was released from the surface holes of the QDs to $\mathrm{Mn}^{2+}$, which considerably improved the RTP intensity of the QDs. ${ }^{20,38}$ In comparison, the radiation center of $\mathrm{Mn}^{2+}$ located in $\mathrm{ZnS}$ crystal lattices, and thereby the relative positions of the excitation and emission spectra, were generally not affected. ${ }^{39}$

\subsection{Interaction between $\mathrm{QDs}^{+}$and ROX-DNA}

Thus, miRNA21 detection could be realized by a phosphorescent probe that was based on the static adsorption between $\mathrm{QDs}^{+}$and ROX-DNA. With the increase of ROX-DNA concentration, the electrostatic interaction shortened the distance between $\mathrm{QDs}^{+}$and ROX-DNA and gradually weakened the RTP of $\mathrm{QDs}^{+}$, accompanied by red shift. This is because the phosphorescence emission spectrum of $\mathrm{QDs}^{+}$was partially overlapped with the absorption spectrum of ROX-DNA (Fig. 4).

When two substances interactively aggregate to form scattering particles, they irradiate significant resonance light scattering (RLS) signals. Fig. 4B shows how the RLS signals of QDs ${ }^{+}$ changed after the addition of ROX-DNA. The RLS intensity was gradually improved by the slow addition of ROX-DNA, indicating $\mathrm{QDs}^{+}$and ROX-DNA had formed larger nanoparticles. This is because the capping of PDADMAC atop the QDS endowed the QDs with positive charge $\left(\mathrm{QDs}^{+}\right)$, while the presence of DNA strands made ROX-DNA negatively-charged in

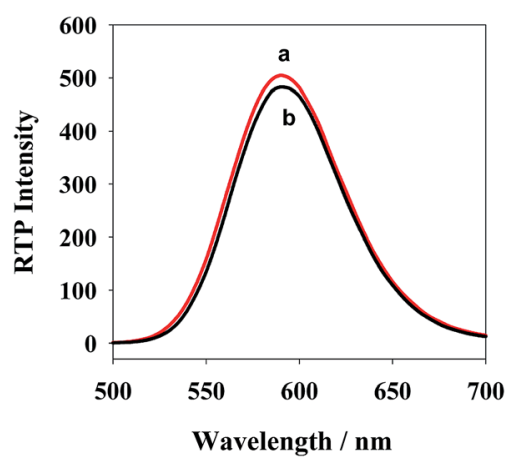

Fig. 3 RTP emission of (a) QDs ${ }^{+}$and (b) Phosphorescence QDs. 

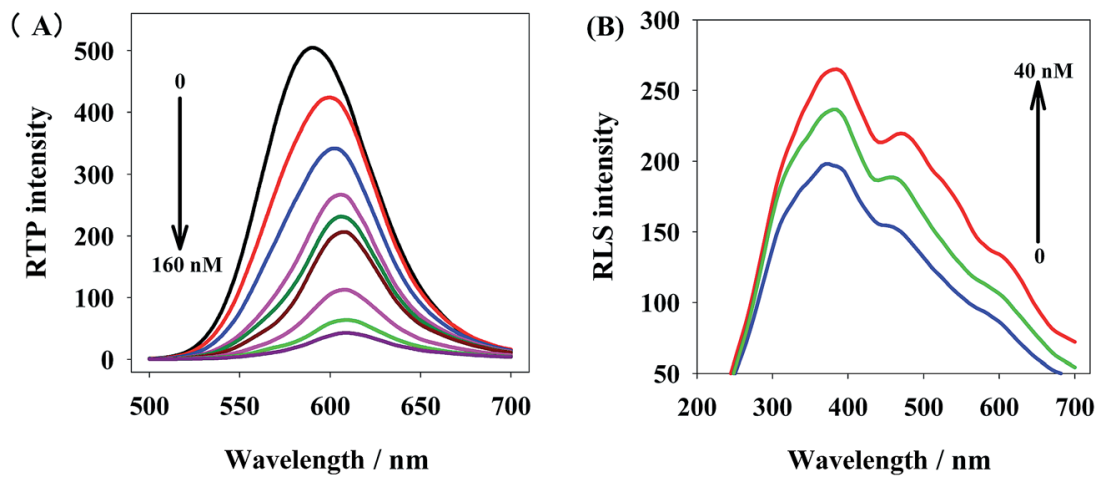

Fig. 4 (A) ROX-DNA concentration-dependent RTP emission of the QDs ${ }^{+}$. The concentration of the QDs ${ }^{+}$is $10 \mathrm{mg} \mathrm{L}^{-1}$. (B) Resonance light scattering spectra of the $\mathrm{QDs}^{+}\left(10 \mathrm{mg} \mathrm{L}^{-1}\right)$ in the presence of various concentrations of ROX-DNA.

weak base solutions ( $\mathrm{pH}$ 7.4). Thus, $\mathrm{QDs}^{+}$and ROX-DNA could electrostatically interact to form larger $\mathrm{QDs}^{+} / \mathrm{ROX}$-DNA nanocomposites.

\subsection{Mechanism of ROX-DNA quenching $\mathrm{QDs}^{+}$}

Phosphorescent quenching is either dynamic or static. During dynamic quenching, the interaction between the excited state molecules of the quencher and the phosphorescent substance leads to a reduction of phosphorescent intensity. This process obeys a Stern-Volmer equation (eqn (2)). During static quenching, the phosphorescent intensity is reduced by the coordination at the ground state between the quencher and the phosphorescent substance that results in the formation of unluminous coordination compounds. This process obeys a Lineweaver-Burk double-reciprocal equation (eqn (3)): $\mathbf{4}^{\mathbf{0 , 4 1}}$

$$
\begin{gathered}
P_{0} / P=1+K_{\mathrm{SV}} C_{\mathrm{q}} \\
1 /\left(P_{0}-P\right)=1 / P_{0}+K_{\mathrm{LB}} /\left(P_{0} C_{\mathrm{q}}\right)
\end{gathered}
$$

where $P_{0}$ is the phosphorescent intensity of the phosphor; $P$ is the phosphorescent intensity after addition of the quencher; $C_{\mathrm{q}}$ is the concentration of the quencher. $K_{\mathrm{SV}}$ is a Stern-Volmer

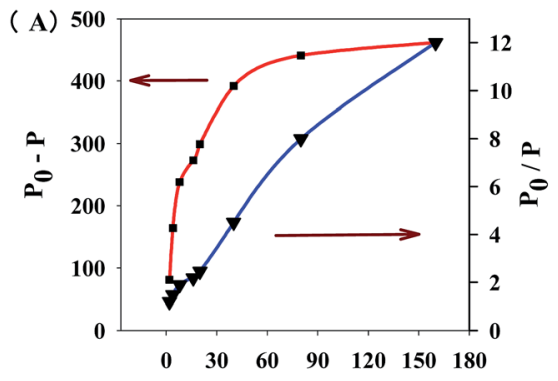

[Target DNA] (nM)

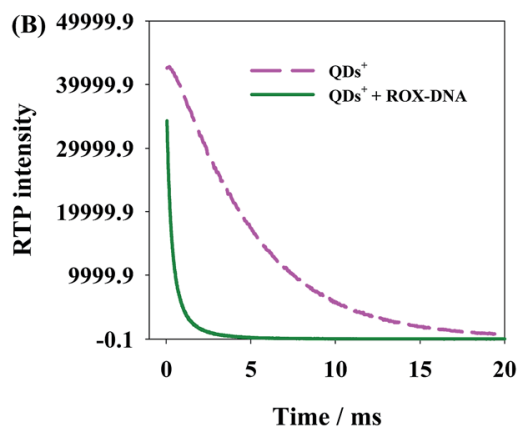

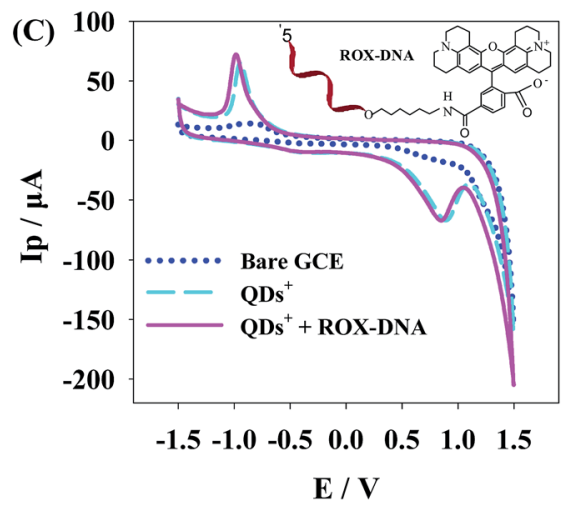

Fig. 5 (A) The Lineweaver-Burk plot and Stem-Volmer plot of phosphorescence quenching of QDs ${ }^{+}$; (B) the decay curves of QDs ${ }^{+}$, and QDs ${ }^{+}+$ ROX-DNA; (C) the cyclic voltammograms of bare glassy carbon electrode (GCE) (blue line), GCE modified with Mn-ZnS QDs ${ }^{+}$(cyan line), and GCE modified $\mathrm{QDs}^{+}+\mathrm{ROX}-\mathrm{DNA}$ mixture (pink line) with a scan rate of $100 \mathrm{mV} \mathrm{s}^{-1-1}$. 

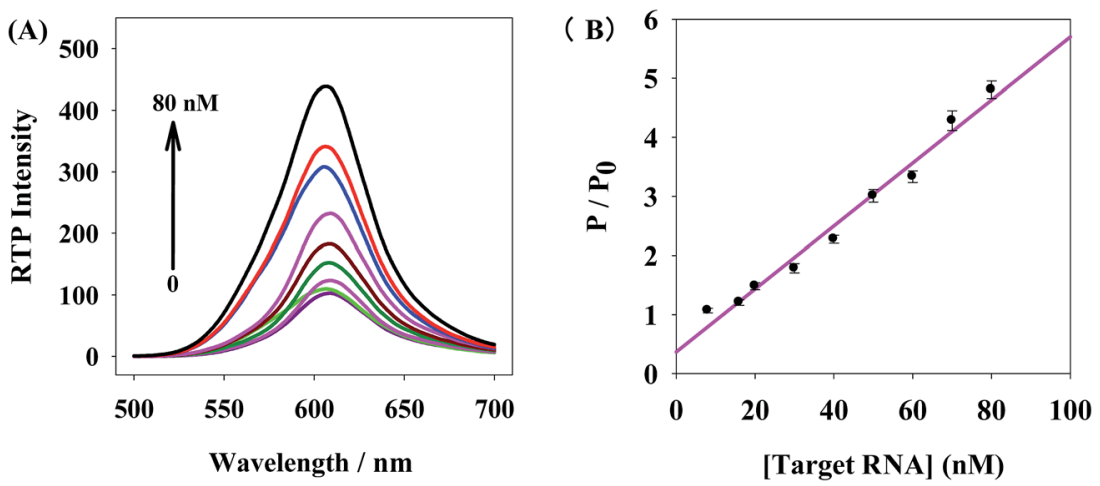

Fig. 6 (A) Target RNA concentration-dependent RTP emission of nanoprobe, (B) dose-response calibration curve for target RNA based on the nanoprobe.

constant and reveals that the phosphorescent molecules and the quencher spread and collide with each other until arriving at a dose-effect balance. $K_{\mathrm{LB}}$ is a static quenching binding constant. ${ }^{42-44}$ Fig. 5A shows the Stern-Volmer curve and Lineweaver-Burk curve fitted from experimental data. Results show that the relationship between $P_{0} / P$ and miRNA21 concentration follows a Stern-Volmer equation, or namely that ROX-DNA dynamically quenches $\mathrm{QDs}^{+}$.

The interaction between ROX-DNA and $\mathrm{QDs}^{+}$was further explored by investigating the phosphorescence lifetime. Fig. 5B shows the phosphorescence lifetime of $\mathrm{QDs}^{+}$, and $\mathrm{QDs}^{+}+\mathrm{ROX}-$ DNA. Results show after capping by PDADMAC, the phosphorescent lifetime of $\mathrm{QDs}^{+}$was $4.9 \mathrm{~ms}$, but after the addition of ROX-DNA, it was shortened to $0.8 \mathrm{~ms}$, which indicates the occurrence of dynamic quenching between $\mathrm{QDs}^{+}$and ROX-DNA.

To validate that the interaction between $\mathrm{QDs}^{+}$and ROX-DNA was PRET rather than electron transfer, we studied the electrochemical properties of this interaction. As showed in Fig. 5C, the oxidation reducing peaks of $\mathrm{QDs}^{+}$and $\mathrm{QDs}^{+}+$ROX-DNA are basically overlapped, so we think only PRET, rather than electron transfer, has occurred. It is probably because the electron transfer depends more on the longer donor-receptor distance, compared with that needed by PRET. ${ }^{45}$ The DNA end of ROX-DNA carried strong negative charge, which shortened the distance between $\mathrm{QDs}^{+}$and ROX-DNA, but the positively-charged $\mathrm{N}^{+}$at the ROX end mutually repelled $\mathrm{QDs}^{+}$, which enlarged that distance. Consequently, PRET occurred between the ROX end and the QDs ${ }^{+}$, but the distance to induce electron transfer was not large enough.

\subsection{QDs $^{+} /$ROX-DNA nanoprobe detecting target RNA sequences}

Fig. 6A illustrates the miRNA21 detection by the QDs $^{+} /$ROX-DNA probes. The addition of different concentrations of miRNA21 gradually restored the RTP intensities of these probes in the range of $0-80 \mathrm{nM}$, indicating these RTP probes are feasible for miRNA21 detection. Based on the above results, we designed $\mathrm{QDs}^{+} /$ROX-DNA RTP nanoprobes for miRNA21 detection. At pH 7.4, the change of RTP intensity of the QDs $^{+} /$ROX-DNA nanoprobe $\left(P / P_{0}\right)$ is linearly associated with the miRNA21 concentration within a certain range (Fig. 6B).
This RTP probes had a linear range of $8-80 \mathrm{nM}$ in miRNA-21 detection, and the linear equation is: $P / P_{0}=0.053 C_{\mathrm{RNA}}+0.367$ $(R=0.989)$, with a detection limit $(3 \sigma)$ of $1.60 \mathrm{nM}$. The solutions without target RNA or with $18 \mathrm{nM}$ miRNA21 were continuously detected for 11 times, and the relative standard deviation (RSD) was $3.4 \%$. The RTP intensity of this system was maintained relatively stable within $60 \mathrm{~min}$ (Fig. S4. $\dagger$ ). This method is superior that it takes advantage of RTP properties of QDs and utilizes PRET to detect specific sequence RNA, so it is not disturbed by the background scattering light or fluorescence from biological fluids, and even eliminates complex pretreatment. This method is feasible for detection of miRNA-21 and biomedical specific RNA.

\subsection{Selectivity of target RNA RTP probe}

We selected some metal ions and biomolecules commonly present in biological fluids and studied their impacts on the miRNA21 probes. With the presence of $50 \mathrm{nM}$ miRNA21, the RTP was not significantly affected by the 6000 -fold dosage of $\mathrm{K}^{+}$, 10000 -fold dosage of $\mathrm{Na}^{+}, 1000$-fold dosage of $\mathrm{Ca}^{2+}, 2000$-fold dosage of $\mathrm{Mg}^{2+}$, 800-fold dosage of glucose, 300-fold dosage of $\mathrm{L}$-cysteine (L-Cys), 300-fold dosage of L-histidine (L-His), or 300 -fold dosage of L-glycin (L-Gly) (Table S2 $\dagger$ ). Since the miRNA21 concentration in the biological samples was far

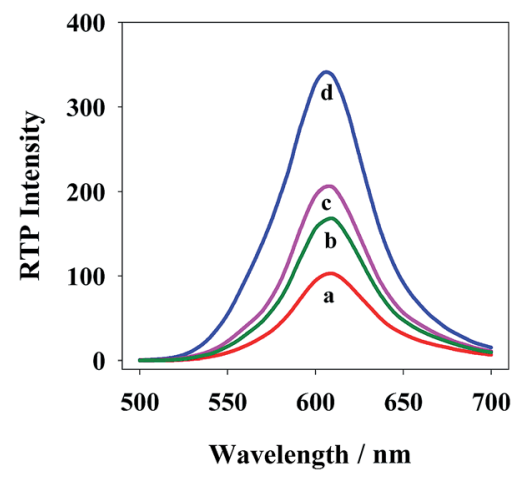

Fig. 7 Normalized spectra of RTP emission of QDs ${ }^{+} /$ROX-DNA (a), $\mathrm{QDs}^{+} / \mathrm{ROX}-\mathrm{DNA}+$ random RNA (b), $\mathrm{QDs}^{+} / \mathrm{ROX}-\mathrm{DNA}+$ mismatch RNA (c) and QDs ${ }^{+} /$ROX-DNA + target RNA (d) excited at $295 \mathrm{~nm}$. 
Table 1 Recovery for the determination of micro-RNA21 in human serum samples (mean $\pm s ; n=3$ )

\begin{tabular}{llr}
\hline Type of samples (\%) & Target RNA spiked (nM) & Recovery \\
\hline Human serum & 10 & $97 \pm 6$ \\
& 50 & $105 \pm 2$
\end{tabular}

beyond the detection limit of $1.60 \mathrm{nM}$, the interferences from common metal ions and biomolecules could be avoided by dilution.

\subsection{Characterization of QDs-DNA as RTP probes}

To validate the performance of the new probes, we added $60 \mathrm{nM}$ miRNA21, $60 \mathrm{nM}$ mismatched RNA or $60 \mathrm{nM}$ random RNA, and found the phosphorescent intensity of $\mathrm{QDs}^{+}$was reduced by $47.2 \%, 20.4 \%$ and $13.1 \%$, respectively (Fig. 7). It is indicated that the new QD probes could effectively detect miRNA21 compared with mismatched or random sequences.

\subsection{Sample analysis}

To further validate whether the new $\mathrm{QDs}^{+} / \mathrm{ROX}-\mathrm{DNA}$ RTP nanoprobes were feasible for miRNA21 detection in human serum, we conducted spiked recycled experiments with human serum and found the miRNA21 concentrations were 10 and $50 \mathrm{nM}$, with spiked recycle rates of $97-105 \%$ (Table 1). The extracts were diluted by 100 times, without any other pretreatment.

\section{Conclusions}

In this study, we built a novel phosphorescence miRNA-21 sequence sensor, based on the phosphorescent resonance energy transfer between $\mathrm{QDs}^{+}$and ROX-DNA, and used it to quantitatively detect the miRNA-21 sequence in biological fluids. This probe had a detection limit of $1.60 \mathrm{nM}$ and a detection range of $8-80 \mathrm{nM}$ on miRNA21. This system is based on the RTP of QDs, thus eliminates the use of deoxidant or other complex pretreatment and avoids the interferences from background fluorescence and scattering light in the biological fluids. Therefore, this system is especially feasible for miRNA21 detection in biological samples, which makes the miRNA-21 detection in biological fluids more simple, cheap and practical.

\section{Conflicts of interest}

There are no conflicts to declare.

\section{Acknowledgements}

This work was supported by the funds of the Natural Science Foundation for Young Scientists of Shanxi Province (201601D021109) and Construction Program of Chemical Advantage and Key discipline of Shanxi Province of China (912019).

\section{References}

1 D. Sidransky, Science, 1997, 278, 1054-1058.

2 H. D. Hill and C. A. Mirkin, Nat. Protoc., 2006, 1, 324-336.

3 D. P. Bartel, Cell, 2004, 116, 281-297.

4 G. A. Calin and C. M. Croce, Nat. Rev. Cancer, 2006, 6, 857866.

5 L. M. Moore and W. Zhang, Expert Opin. Ther. Targets, 2010, 14, 1247-1257.

6 S. D. Selcuklu, M. T. A. Donoghue and C. Spillane, Biochem. Soc. Trans., 2009, 37, 918-925.

7 A. M. Krichevsky and G. Gabriely, J. Cell. Mol. Med., 2009, 13, 39-53.

8 P. P. Medina, M. Nolde and F. J. Slack, Nature, 2010, 467, 8690.

9 R. Shi and V. L. Chiang, Biotechniques, 2005, 39, 519-525.

10 E. Varallyay, J. Burgyan and Z. Havelda, Nat. Protoc., 2008, 3, 190-196.

11 Y. Wen, H. Pei, Y. Shen, J. Xi, M. Lin, N. Lu, X. Shen, J. Li and C. Fan, Sci. Rep., 2012, $2,867$.

12 H. Yin, Y. Zhou, H. Zhang, X. Meng and S. Ai, Biosens. Bioelectron., 2012, 33, 247-253.

13 L. P. Lim, N. C. Lau, P. Garrett-Engele, A. Grimson, J. M. Schelter, J. Castle, D. P. Bartel, P. S. Linsley and J. M. Johnson, Nature, 2005, 433, 769-773.

14 J. L. Abell, J. M. Garren, J. D. Driskell, R. A. Tripp and Y. Zhao, J. Am. Chem. Soc., 2012, 134, 12889-12892.

15 J. M. Costa-Fernández, R. Pereiro and A. Sanz-Medel, TrAC, Trends Anal. Chem., 2006, 25, 207-218.

16 Y. He, H.-F. Wang and X.-P. Yan, Anal. Chem., 2008, 80, 38323837.

17 P. Wu, Y. He, H.-F. Wang and X.-P. Yan, Anal. Chem., 2010, 82, 1427-1433.

18 J. M. Traviesa-Alvarez, I. Sánchez-Barragán, J. M. CostaFernández, R. Pereiro and A. Sanz-Medel, Analyst, 2007, 132, 218-223.

19 E. Sotelo-Gonzalez, M. T. Fernandez-Argüelles, J. M. CostaFernandez and A. Sanz-Medel, Anal. Chim. Acta, 2012, 712, 120-126.

20 Y. He, H.-F. Wang and X.-P. Yan, Chemistry, 2009, 15, 54365440.

21 R. Thakar, Y. Chen and P. T. Snee, Nano Lett., 2007, 7, 34293432.

22 H.-F. Wang, Y. He, T.-R. Ji and X.-P. Yan, Anal. Chem., 2009, 81, 1615-1621.

23 Y. Miao, Z. Zhang, Y. Gong, Q. Zhang and G. Yan, Biosens. Bioelectron., 2014, 52, 271-276.

24 Y. Miao, RSC Adv., 2015, 5, 76804-76812.

25 Y. Miao, Sensing and Bio-Sensing Research, 2015, 5, 112-116. 26 Y. Li, Y.-M. Miao, M.-Q. Yang, Y.-X. Wu and G.-Q. Yan, Chin. Chem. Lett., 2016, 27, 773-778.

27 Y. Miao, J. Lv, Y. Li and G. Yan, RSC Adv., 2016, 6, 109009109022.

28 Y. Miao, M. Yang and G. Yan, RSC Adv., 2016, 6, 8588-8593. 29 Y. Miao, Y. Li, Z. Zhang, G. Yan and Y. Bi, Anal. Biochem., 2015, 475, 32-39. 
30 Y. Miao, Z. Zhang, Y. Gong and G. Yan, Biosens. Bioelectron., 2014, 59, 300-306.

31 J. Lv, Y. Miao, J. Yang, J. Qin, D. Li and G. Yan, Biosens. Bioelectron., 2017, 91, 560-565.

32 I. Yildiz, M. Tomasulo and F. M. Raymo, Proc. Natl. Acad. Sci. U. S. A., 2006, 103, 11457-11460.

33 P. R. Fortes, C. Frigerio, C. I. C. Silvestre, J. L. M. Santos, J. F. C. Lima and E. A. G. Zagatto, Talanta, 2011, 84, 13141317.

34 D. J. Norris, A. Sacra, C. B. Murray and M. G. Bawendi, Phys. Rev. Lett., 1994, 72, 2612-2615.

35 V. I. Klimov, J. Phys. Chem. B, 2000, 104, 6112-6123.

36 O. Kulakovich, N. Strekal, A. Yaroshevich, S. Maskevich, S. Gaponenko, I. Nabiev, U. Woggon and M. Artemyev, Nano Lett., 2002, 2, 1449-1452.

37 P. Anger, P. Bharadwaj and L. Novotny, Phys. Rev. Lett., 2006, 96, 113002.
38 Y. Hou, J. Ye, Z. Gui and G. Zhang, Langmuir, 2008, 24, 96829685.

39 W. U. Huynh, J. J. Dittmer and A. P. Alivisatos, Science, 2002, 295, 2425-2427.

40 J. R. Lakowicz and G. Weber, Biochemistry, 1973, 12, 41614170.

41 K. Sauer, H. Scheer and P. Sauer, Photochem. Photobiol., 1987, 46, 427-440.

42 R. M. Jones, T. S. Bergstedt, D. W. McBranch and D. G. Whitten, J. Am. Chem. Soc., 2001, 123, 6726-6727.

43 C. B. Murphy, Y. Zhang, T. Troxler, V. Ferry, J. J. Martin and W. E. Jones, J. Phys. Chem. B, 2004, 108, 1537-1543.

44 M. S. Baptista and G. L. Indig, J. Phys. Chem. B, 1998, 102, 4678-4688.

45 M. D. Newton, Chem. Rev., 1991, 91, 767-792. 